$\xi=-1$

\title{
Three-dimensional Stress Analysis Study on Multi-Bolted Joints of Composite Plates
}

\author{
Khairi Supar ${ }^{1 *}$, Hilton Ahmad ${ }^{1}$, Lee Sim Yee ${ }^{2}$ \\ ${ }^{1}$ Faculty of Civil and Environmental Engineering, Universiti Tun Hussein Onn Malaysia, 86400 Parit Raja, Batu Pahat, Johor Darul \\ Ta'zim \\ ${ }^{2}$ Faculty of Engineering and Information Technology, MAHSA University, Jenjarom \\ *Corresponding author E-mail: khairisupar@gmail.com
}

\begin{abstract}
Single-lap bolted joint is the widely applied technique in joining parts of aerospace and civil engineering structures, due to joint efficiencies where staggered arrangements are commonly adopted. This particular joint type exhibits secondary bending phenomenon due to eccentric loading path. Stress analysis enables the structure engineers to predict the failure path and maximum stress that may lead to catastrophic failures. Stress analysis study were carried out in multi-bolted woven fabric kenaf reinforced polymer (WKRP) joints with variation of lay-up types, hole configurations and plate thicknesses. 3-D FEA modelling implemented here explicitly incorporates out-ofplane deformation to provide better prediction upon crack initiation from maximum stress exhibited along the hole boundary. WKRP plates tested were failed in net-tension where the crack propagated normal to its applied stress. It was found that plate variation (i.e., layup types, hole configurations and plate thicknesses) correspondingly affect tangential stress distributions along its hole boundary. Current 3-D models used modulus properties from independent experimental work which regarded as smeared-out properties through their plate thickness. Staggered configurations demonstrated more evenly stress distribution to their adjacent bolts due to stress resistance diagonally and larger staggered plate width. Slightly contrast in lay-up types where larger tangential stress is exhibited in cross-ply due to more volume fraction of $0^{\circ}$ fiber direction. Larger tangential stress in thicker plates associated to effective friction stress transfer to give higher failure load. Effects of secondary bending is more prominent in cross-ply and thinner plates, assumption of smeared-out properties is less good due to plate edge lifting, however, effect of secondary bending phenomenon in multi-bolted is lesser than single-bolted joints.
\end{abstract}

Keywords: Stress analysis; Multi-bolts; Single-lap joint; Composite plate; FEA.

\section{Introduction}

Composites materials is commonly used as a part in structural applications in various engineering sectors especially in bridge and housing constructions due to outstanding specific stiffness and strength. Materials engineers and scientists worldwide are competing to produce a high-performance engineering material that has excellent mechanical properties coupled with lightness to optimize "fuel-efficiency" structures during design, transportation and erection stages. Constituent materials are combined to form a composite material usually have enhanced characteristics which differ from their origin materials [1]. Joining techniques such as mechanically-fasteners, adhesively-bonded and welded (more prominent in metal plates joints) are commonly used, the first technique is widely adopted for easier disassembles for repair and monitoring works. In structures application, multi-bolted joints are designed in construction and manufacturing industries due to joint efficiency. Most research available in the literatures were limited to single-bolted joint due to simplicity, but due to by-pass loading to adjacent bolts only can be captured within multi-bolted joints leading to net-tension failure in later case [2]. Progressive bearing stress at failures exhibited much more complex damage mechanisms than catastrophic net-tension failures primarily reliant on clamping load, lay-up types and bolts arrangements [3]. Single-lap joint is associated to less weight penalty in structures design, however subjected to secondary bending due to unsymmetrical loading path. Therefore, extra tensile stress exhibited in single-lap joints gives less loading capacity than double-lap joints [3].

Due to discontinuities in composite parts, stress concentration occurred at the notch tip usually normal to the applied load. Anders and Ahmad [4] has carried out experimental work on notched woven fabric kenaf reinforced polymer (WKRP) plates and found that notched strength is largely dependent upon hole size, plate thickness and stacking orientations. Cunningham et al. [5] has carried out a series of unidirectional glass fiber reinforced polymer (GFRP) plates of various non-staggered and staggered configurations and found that later configurations promote higher netsectional strength due to larger length of failure path in 'zig-zag' pattern, however complex fracture paths were exhibited depending upon gage length, pitch distance and number of staggered hole. Experimental investigations on single-row CFRP three-bolts joints were investigated by McCarthy and Gray [6] and found that increased equally pitch distance, diameter of middle bolt, plate width leading to more evenly load sharing among adjacent bolts. This corresponds to ability of joining plates to carry higher applied load as stress transfer to adjacent bolts were almost uniform. Zhou et al. [7] carried out experimentally multi-bolted joints on preimpregnated CFRP and found that two ultimate failure types occurred where net-tension at either one of the outer bolts (where similar CFRP joining plates were used). The failure occurred due to several factors such as secondary bending exhibited at outer bolts, crack growth is initiated from the bottom plane towards top plane.

Copyright $(92018$ Authors. This is an open access article distributed under the Creative Commons Attribution License, which permits unrestricted use, distribution, and reproduction in any medium, provided the original work is properly cited. 
DeJong [8] proposed closed-form expression to carry out stress analysis study of pin-loaded hole in quasi-isotropic composites using superposition method. Stress distribution expressions includes radial stress, $\sigma_{r}$, tangential stress, $\sigma_{\theta}$ and shear stress, $\tau_{x y}$ along the hole boundary by assuming rigid pin and implementation of cosinusoidal radial stress distribution to indicate the existence of bearing from the pin. Smith et al. [9] expanded deJong work to incorporates clamp-up effect, producing more comprehensive closed-form expression. Recently, due to advanced computing technology has led to evolution in numerical work, in particular finite element analysis (FEA) framework in stress analysis study. Ahmad et al. $[10,11]$ compared stress distribution of single-bolted CFRP plates from analytical expression [8] and carried out 3-D FEA modelling in double-lap joints [10] and single-lap joints [11]. It was found that FEA modelling able to capture more physically realistic results than analytical expression [8] due to simplistic assumption in pin contact interactions. They also found from FEA modelling gives relatively higher tangential stress due to FEA has accounted for finite width effect and analytical expression unable to include friction load transfers effects of frictional contact between the bolt and inner hole.

There were limited reported literatures available to propose analytical expressions and numerical works on stress distribution study in multi-bolted joints. Feo et al. [12] study showed good agreement in stress distribution study of multi-bolted joint with various bolts numbers in non-staggered GFRP joining plates. They found that applied stress was not uniformly distributed due to varying bolt position, hole clearance, bolt-torque, friction between member plates and washer-plate interface. Higher bearing stresses and deformations from both experimental results and FEA output were exhibited at the exterior column due to decreasing washer pressure at the exterior column as sliding occurred. Consistence findings were also found in Yun et al. [13] in their FEA study of multibolted CFRP joints to determine the deformation shape and associated hole clearances. They found that holes clearance in composites plates was higher at the exterior column (i.e., closest to the applied loading) and hole elongations decreased as further away from applied load. They also found that the highest failure index and net-tension failure was occurred at exterior column, consistence with experimental findings.

Current work implemented a 3-D FEA model to study stress analysis on multi-bolted WKRP joints. The modelling framework were explicitly modelled frictional load transfer, clamping load and surface interactions by using ABAQUS CAE Version 6.13. The stress distribution implemented here were following experimental datasets [14], subsequently discussed in discussion section.

\section{FEA Modelling technique and approach}

\subsection{Testing series and generation of elastic properties}

All testing series modelling developed in the present work were idealized as half-models (except in configuration D as full model due to absence of symmetrical axis) in three-dimensional modelling framework following experimental configurations to reduce computational cost and time effort. The models were explicitly includes clamping load and surface interactions. The bolt head, bolt shaft and nut were modelled as a single unit where the clamping load were assigned within internal surface of bolt shaft as suggested by ABAQUS CAE documentation. The washers were separately model to allow explicitly included frictional load transfer within joining plates. Perfect-fit conditions between bolt shaft and bore hole were assumed in all models to eliminate the effect of clearance.

The boundary conditions and applied displacements were assigned accordingly to resemble mechanical testing conditions. As described earlier, elastic properties of woven fabric kenaf reinforced polymer (WKRP) used in the present model were obtained from independent experimental set-up and were considered as "smeared-out" properties, given in Table 1 below. On the other hand, out-of-plane properties were determined from expression available from literatures [3]. Current works were carried out cross-ply (PX2 and PX4) and quasi-isotropic lay-ups (PQ4), and the symbol 's' in lay-up column refer to "symmetry".

\begin{tabular}{l|c|c|c|c|c|c}
\multicolumn{6}{c}{ Table 1: Material properties of WKRP lay-up used in current work } \\
\hline Lay-up & $\begin{array}{l}E_{x} / E_{y} \\
(\mathrm{MPa} \\
)\end{array}$ & $\begin{array}{l}E_{z} \\
(\mathrm{MPa} \\
)\end{array}$ & $\begin{array}{c}V_{x y} / V_{y z} / V_{x} \\
z\end{array}$ & $\begin{array}{c}G_{x y} \\
(\mathrm{MPa} \\
)\end{array}$ & $\begin{array}{c}G_{y z} \\
(\mathrm{MPa} \\
)\end{array}$ & $\begin{array}{c}G_{x z} \\
(\mathrm{MPa} \\
)\end{array}$ \\
\hline $\begin{array}{l}\text { PX2 } \\
\left(0^{\circ} / 90^{\circ}\right)_{\mathrm{s}}\end{array}$ & 2260 & 565 & 0.1 & 198 & 182 & 182 \\
$\begin{array}{l}\mathrm{PX} 4 \\
\left(0^{\circ} / 90^{\circ} \mid 90^{\circ} / 0^{\circ}\right.\end{array}$ & 2291 & 573 & 0.1 & 201 & 184 & 184 \\
)$_{\mathrm{s}}$ & & & & & & \\
$\begin{array}{l}\mathrm{PQ} 4 \\
\left(0^{\circ} / 90^{\circ} \pm 45^{\circ}\right)_{\mathrm{s}}\end{array}$ & 2009 & 661 & 0.3 & 755 & 220 & 220 \\
\hline
\end{tabular}

The testing series implemented in current work comprised of six multi-bolts configurations as given in Figure 1 comprised of three non-staggered and three staggered configurations. Circular holes with $5 \mathrm{~mm}$ diameter, $d$ was drilled according to specified bolt location. The end distance, $e_{1}$ and edge distance, $e_{2}$ were respectively set constant to $3 d$ and the normalised pitch distance, $p / d$ is 4 [15]. Spacing between nearest adjacent holes were given as symbol $p$ and $g$ respectively.

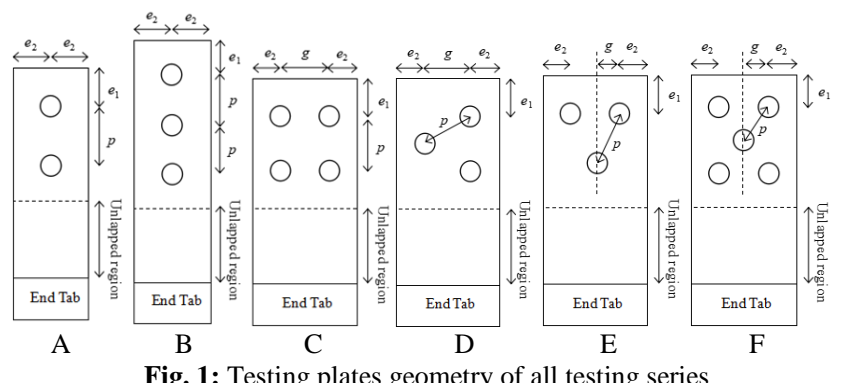

\subsection{Loading and boundary conditions}

Boundary condition at far-left is held fixed and applied stresses (28 MPa) was assigned at the far-right as shown in Figure 2 below. All surface interactions were modelled as "master-slave" interactions and friction coefficient of 0.3 and 0.1 were assigned between composite-composite and composite-steel surfaces respectively. Master surface was assigned within larger modulus surfaces and exhibited less deformable than weaker surface materials (assigned with slave surface correspondingly). The contact interaction surfaces were set as small sliding formulation and surface-to-surface discretization method, combination of each gives more realistic physical perturbation and able to cover larger contact area between contact pairs. Y-symmetry was assigned at the $\mathrm{y}$-axis to represent half-model configurations as idealized.

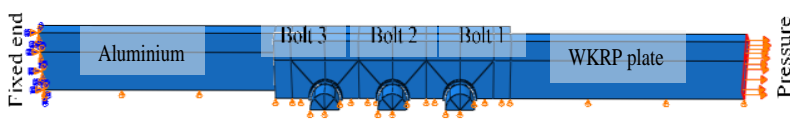

Fig. 2: Boundary condition and loading applied of 3-D multi-bolted joints model (the bolts position were labelled accordingly)

The procedure to assign clamping loads were followed as suggested by ABAQUS CAE 6.13 documentation [16], where the bolt is assigned with pre-tensioned load prior to far-field stress applied. A $1000 \mathrm{~N}$ clamping load was applied in each bolt by applying pretension force within internal region of bolt shaft during preloading step (Step 1). Subsequently the clamping load was kept constant (fix at current length) in the loading step (Step 2) to idealize application of clamping load immediately prior to mechanical testing. Concurrently, constant pressure was applied at the farright edge in Step 2. The mesh ahead of hole edge (particularly 
area under washers) were refined and remaining plate regions were made coarser to save computational effort as shown in Figure 3. Second-order brick elements with element designation code of C3D20 (a 20-node quadratic brick) was used as element type, better representation of bending deformation can be exhibited as shear locking is eliminated (profound among first-order elements). These elements were chosen mainly due to effect of secondary bending can be explicitly demonstrated.

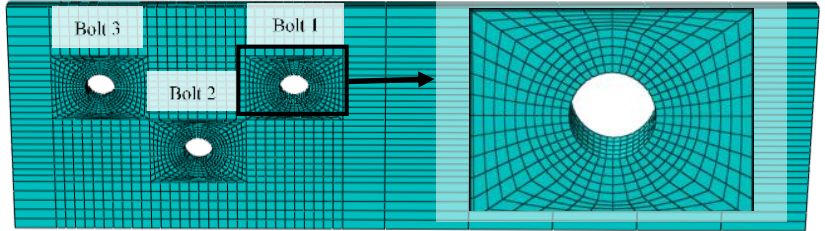

Fig. 3: Meshing of 3-D multi-bolted joints model based on experimental plate geometry (the notch edge at Bolt 1 is enlarge for visual clarity)

\section{Results and discussion}

\subsection{Effect of lay-up types}

Figure 4 showed stress distribution in configuration D of quasiisotropic (PQ4) and cross-ply (PX4) lay-ups, both plates has nominal thickness of $4 \mathrm{~mm}$. Three types of stresses along the hole boundary is drawn, i.e., tangential stress and radial stress as given in Figure 4 and 5 respectively. In cross-ply with highly orthotropic $0^{\circ} / 90^{\circ}$ fiber arrangement gives significantly high tangential stress at approximately $85^{\circ}$ (where bearing region started) due to larger fiber volume fraction of $0^{\circ}$ fiber directions than quasi-isotropic counterpart. Bear in mind that the stress is applied at $0^{\circ}$ direction parallel to $0^{\circ}$ fiber angle to give more tangential stress. On the other hand, absence of $\pm 45^{\circ}$ layer demonstrated two peak tangential stress (second peak is significantly larger than its first peak) to give negligible tangential stress value at an angle of $45^{\circ}$ and $135^{\circ}$. In quasi-isotropic lay-up, stress distributions are more evenly distributed from angle $0^{\circ}$ to $90^{\circ}$ along its hole boundary. Tangential stress is associated to stress concentration effects, crack initiation and propagation occurred normal to the applied stress (orthogonally to the maximum principal stress).
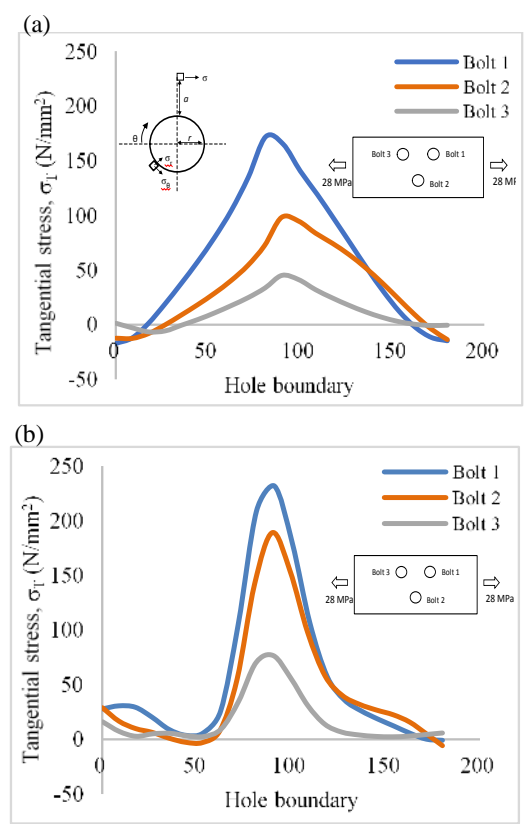

Fig. 4: Tangential stress distribution along hole boundary in configuration D (a) PQ4 (b) PX4

Figure 5 showed radial stress along hole boundary in both lay-up types, zero radial stress beyond $85^{\circ}$ is due to non-contact region as hole clearance is taken-up by the bolt shaft. The negative sign in radial stress denotes the compression exhibited beneath the bolt shaft due to bearing between bolt shaft and plate bore. It is expected that hole elongation in $\mathrm{PQ} 4$ is higher than PX4 due to more $0^{\circ}$ fiber volume in latter lay-up, however the findings showed otherwise. Current work compares both lay-ups in staggered arrangement, due to existence of $\pm 45^{\circ}$ layers promotes resistance of fiber diagonally to refrain the hole elongation in quasi-isotropic, on contrary smaller $0^{\circ}$ volume fiber, $V_{f}$ in quasi-isotropic gives larger hole elongation. However, the former effect is more prominent has led to slightly larger radial stress due to compression from bearing. The effects are reduced almost linearly as bolts is getting further from applied stress. Note that secondary bending effect is more prominent in cross-ply lay-up, therefore much lesser radial stress in outmost bolt (Bolt 1) is much expected as extra tensile stress exhibited may offset the compression stress due to bearing. Bearing stress is largely associated to bearing failure mode associated to fiber kinking, matrix compression due to bearing effect beneath the bolt shaft. The radial stress value is significantly small compared to tangential stress (from Figure 4) to promote net-tension failures to occur.
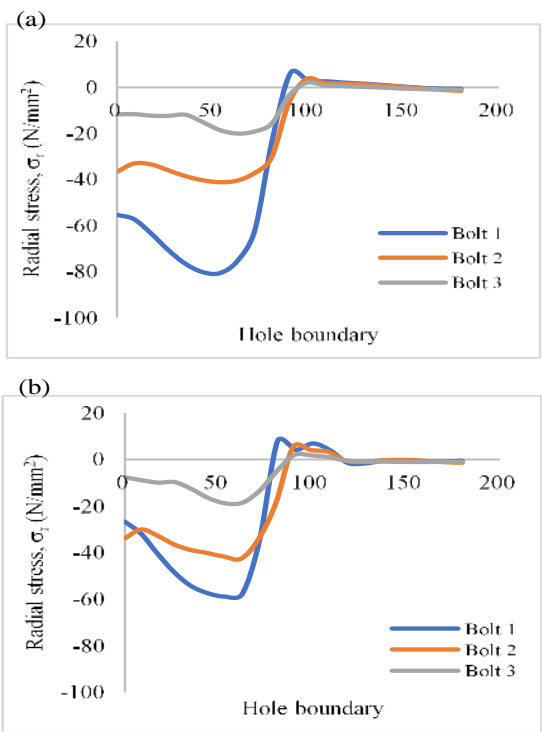

Fig. 5: Radial stress distribution along hole boundary in configuration D (a) PQ4 (b) PX4

\subsection{Effect of hole configurations}

Figure 6 shows tangential stress along hole boundary in PQ4 of all configurations investigated with uniform applied stress of $28 \mathrm{MPa}$ (denotes as $90 \%$ failure load level). It was found that highest tangential curve in Bolt 1 (generally the outermost bolt from applied loading) of all configurations compared to much lower tangential stress given in Bolt 2 and to the lesser extent in Bolt 3. It is much expected that Bolt 1 exhibited largest tangential stress as it is the first bolt to exhibit bearing as slip was taken place (slip occurred as applied bolt, $P_{a p p}$ surpassed clamping load, $\left.P_{b o l t}\right)$. Tangential stress is associated with non-uniformity of stress profile resulting to stress concentration and largest stress concentration were occurred at an angle of approximately $85^{\circ}$ (direction of angle is shown in Figure 6) to signifies of crack initiation at the hole boundary.

Theoretically, in multi-bolts configurations, outer bolt can transfer friction stress known as "by-pass loading", subsequently enhanced their loading resistance in Bolt 1 as it can transfer bearing stress to its adjacent bolts. In staggered hole configurations (configuration $\mathrm{D}, \mathrm{E}$ and $\mathrm{F}$ ) gives highest tangential stress, $\sigma_{T}$ along hole boundary than non-staggered configuration due to resistance stress diagonally and coupled with larger staggered plate width (due to requirement from code provisions). On the contrary, stress transfer in 
non-staggered occurred parallel to applied stress may not optimize the benefit from angle-plies. All configurations were exhibited larger elongations (hence, larger tangential stress) at outmost bolt (i.e., Bolt 1) than other adjacent bolts.
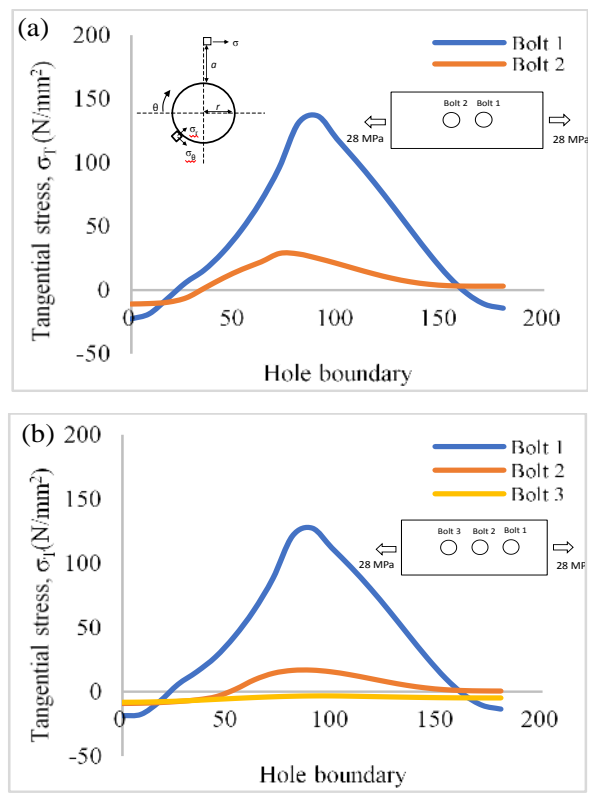

Fig. 6: Stress distribution along hole boundary in non-staggered arrangements with various bolt numbers (a) configuration A (b) configuration B

It is expected that in a single row of non-staggered arrangement promotes less tangential stress with lower bolt numbers due to ability of friction transfer to adjacent bolts. Configuration B which has three bolts in a row demonstrated slightly lower tangential stress than two bolts in configuration A. It was also found that the tangential stress in adjacent bolt is reduced significantly as shown in Bolt 2, to more lesser extent in Bolt 3 of configuration B (where tangential stress in Bolt 3 is negligible). From the stress analysis, we can conclude that in non-staggered arrangement, numbers of bolts ahead of outermost most is not contributing much to the stress transfer. Due to large tangential stress in outer bolt, it is much expected the net-tension failure occurred in Bolt 1 .

Similar tangential stress plots were exhibited in non-staggered arrangement with increased number of rows (i.e., configuration A and C). This is closely related to "finite width" effect where in a vertical line of configuration $\mathrm{C}$ is smaller than Configuration $\mathrm{A}$ (although larger plate width in latter configuration but presence of more bolts initiated larger net stress concentration and thus increased tangential stress value) as shown in Figure 7. It was also found that tangential stress in Configuration $\mathrm{C}$ is higher to suggest that better stress transfer if adjacent bolt is arranged in row rather than in column arrangement. Again, due to large tangential stress in outer bolt, it is much expected that net-tension failure occurred within exterior row in both configurations. From stress-strain relationship, increasing hole elongation of composite plate (associated to plate displacement) exhibited higher stress at the notch tip.

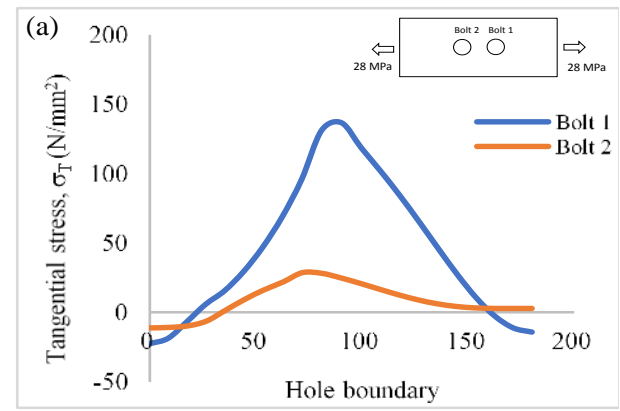

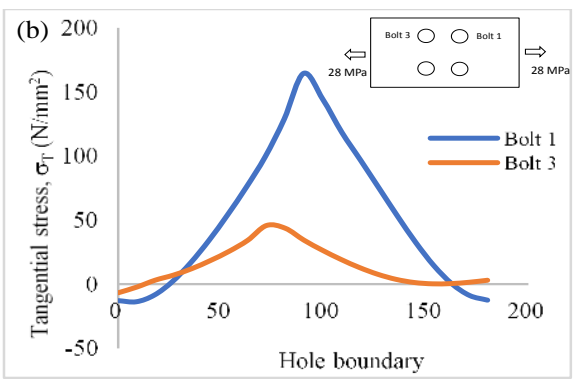

Fig. 7: Stress distribution along hole boundary in (a) configuration A (b) configuration $\mathrm{C}$

In comparison of staggered bolts arrangement (with constant bolt number) in Figure 8 between configuration $\mathrm{D}$ and $\mathrm{E}$, tangential stress in both configurations are almost identical. Although larger plate width in configuration $\mathrm{E}$, but due to existence of two bolts in a vertical line has led to larger net sectional area that promotes comparable tangential stress with configuration D. It is expected that bearing stress (given as ultimate load divided by net crosssectional area) is almost similar in both configurations where larger net-sectional area in latter configuration. Note that staggered configuration has better stress transfer as given in Bolt 2 has larger tangential stress than Bolt 2 in non-staggered counterparts as given in Figure 6).
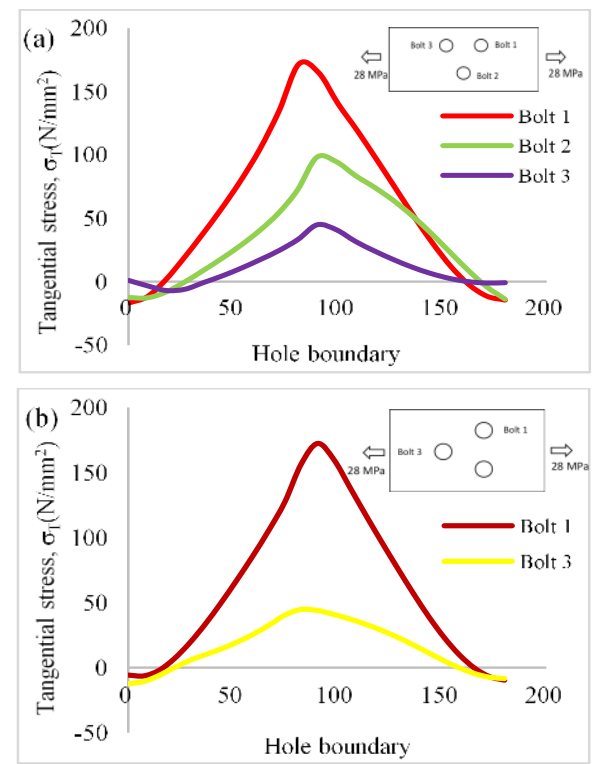

Fig. 8: Stress distribution along hole boundary in (a) configuration D (b) configuration $\mathrm{E}$

Figure 9 compares between bolt numbers in staggered arrangement of similar plate width. Bear in mind that the first two columns from exterior row is similar in both configuration with additional column with 2 bolts in configuration $\mathrm{F}$. It was found that slightly lower tangential stress in configuration $\mathrm{F}$ due to more bolts numbers and better by-pass stress being transferred to adjacent bolts. However, tangential stress curve at Bolt 3 and 4 in configuration $\mathrm{F}$ showed quite similar, suggesting even stress transfer in staggered arrangement (however, this value is significantly low compared to Bolt 1). It is suggested that the stress is effectively transferred when arranged diagonally where angle-ply able to resist hole elongation to promote lesser hole deformation. It was found that less hole deformation occurred in configuration $\mathrm{F}$ as lesser bending deformation due to presence of more bolt in diagonal directions. 

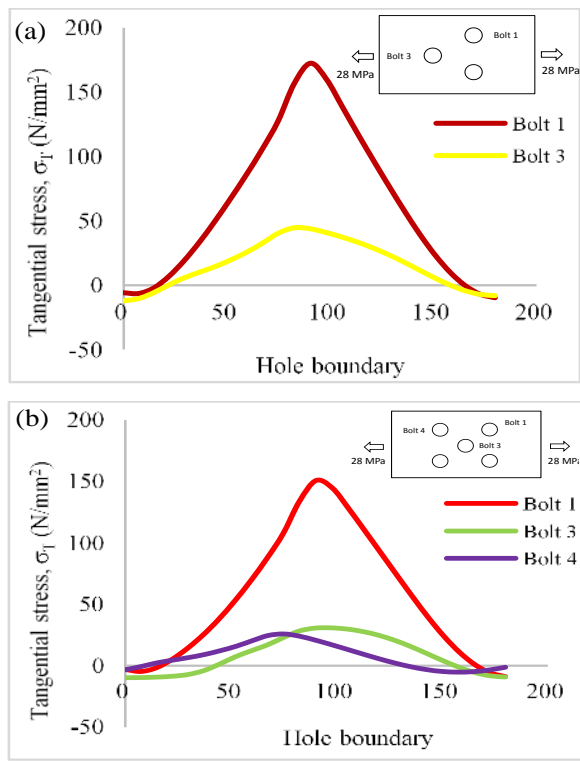

Fig. 9: Stress distribution along hole boundary in (a) configuration E (b) configuration $\mathrm{F}$

\subsection{Effect of plate thickness}

Plates thickness is associated to effect of plates bending and stress transferred through plate thickness. It is expected that better load transfer occurred in thicker plates, suggesting to better load transfer in friction. As shown in Figure 10, thicker plate has larger tangential stress associated to better friction stress transfer in a joint. It was also found that Bolt 2 in thicker plates has more tangential stress than thinner plates to promote better effect from bypass stress transfer.
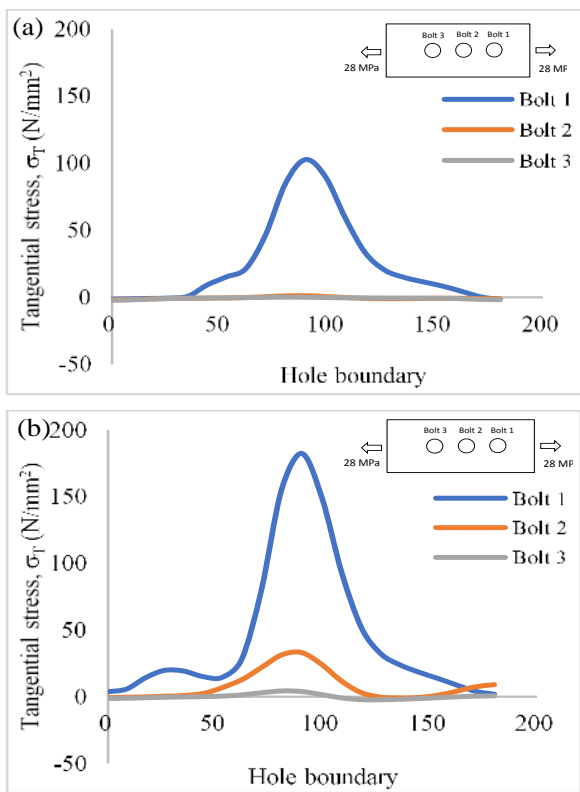

Fig. 10: Stress distribution along hole boundary on configuration B (a) PX2 (b) PX4

The thicker WKRP plates gives lower secondary bending deformation as expected. Implementation of smeared-out properties may give less good representation in secondary bending, especially in plates with larger edge lifting. However secondary bending in multi-bolts are less significant than single-bolt joints due to adjacent bolts able to restrain the plate edge bending as sliding occurred. From the stress distribution, it is expected that thinner plate failed in lower peak load and inability of adjacent bolt to transfer stress has led to detrimental effects. Correspondingly, high load capacity exhibited in thicker plate and indirectly promotes larger resistance to applied loading.

\subsection{Effect of secondary bending}

Table 2 shows hole elongation and plate lifting from secondary bending effects in all configuration investigated. As been mentioned previously, increasing number of bolt promotes lower tangential stress at the hole edge due to by-pass stress is effectively transferred to their adjacent bolts. Moreover, the load capacity is also affected by hole elongations as high elasticity deformation in WKRP plates able to accommodate applied load. Hole 1 showed the largest hole elongations due to the first bearing contact was located at Bolt 1 and reduced significantly as goes further from its respective outer bolt.

Table 2: Hole deformation in each hole and associated plate lifting deformation due to secondary bending

\begin{tabular}{|c|c|c|c|c|c|c|c|}
\hline \multirow{3}{*}{$\begin{array}{l}\text { Lay- } \\
\text { up }\end{array}$} & \multirow{3}{*}{ Config } & \multirow{3}{*}{$\begin{array}{c}\text { Max. } \\
\text { stress } \\
\left(\mathrm{N} / \mathrm{mm}^{2}\right)\end{array}$} & \multicolumn{4}{|c|}{ Hole elongations $(\mathrm{mm})$} & \multirow{3}{*}{$\begin{array}{c}\text { Secondary } \\
\text { bending } \\
(\mathrm{mm})\end{array}$} \\
\hline & & & \multirow{2}{*}{$\begin{array}{c}\text { Position } \\
\text { hole }\end{array}$} & \multicolumn{3}{|c|}{ Hole } & \\
\hline & & & & 1 & 2 & 3 & \\
\hline \multirow{14}{*}{ PQ4 } & \multirow{2}{*}{$\begin{array}{c}\text { Single- } \\
\text { bolt }\end{array}$} & \multirow{2}{*}{1005} & Top & 0.31 & - & - & \multirow{2}{*}{0.68} \\
\hline & & & Bottom & 0.11 & - & - & \\
\hline & \multirow{2}{*}{ A } & \multirow{2}{*}{559} & Top & 0.20 & 0.05 & - & \multirow{2}{*}{0.26} \\
\hline & & & Bottom & 0.28 & 0.07 & - & \\
\hline & \multirow{2}{*}{ B } & \multirow{2}{*}{495} & Top & 0.18 & 0.03 & 0.00 & \multirow{2}{*}{0.25} \\
\hline & & & Bottom & 0.27 & 0.04 & 0.01 & \\
\hline & \multirow{2}{*}{$\mathrm{C}$} & \multirow{2}{*}{557} & Top & 0.23 & 0.06 & - & \multirow{2}{*}{0.25} \\
\hline & & & Bottom & 0.30 & 0.08 & - & \\
\hline & \multirow{2}{*}{ D } & \multirow{2}{*}{769} & Top & 0.28 & 0.19 & 0.07 & \multirow{2}{*}{0.53} \\
\hline & & & Bottom & 0.36 & 0.22 & 0.08 & \\
\hline & \multirow{2}{*}{$\mathrm{E}$} & \multirow{2}{*}{731} & Top & 0.27 & 0.08 & - & \multirow{2}{*}{0.25} \\
\hline & & & Bottom & 0.34 & 0.12 & - & \\
\hline & \multirow{2}{*}{$\mathrm{F}$} & \multirow{2}{*}{568} & Top & 0.23 & 0.04 & 0.03 & \multirow{2}{*}{0.25} \\
\hline & & & Bottom & 0.30 & 0.08 & 0.05 & \\
\hline \multirow{4}{*}{ PX4 } & \multirow{2}{*}{ B } & \multirow{2}{*}{582} & Top & 0.27 & 0.04 & 0.02 & \multirow{2}{*}{0.27} \\
\hline & & & Bottom & 0.37 & 0.05 & 0.01 & \\
\hline & \multirow{2}{*}{ D } & 598 & Top & 0.41 & 0.37 & 0.11 & \\
\hline & & 398 & Bottom & 0.50 & 0.41 & 0.13 & 0.64 \\
\hline PX2 & $B$ & 454 & Top & 0.18 & 0.02 & 0.01 & 039 \\
\hline $\mathrm{F} A 2$ & B & 454 & Bottom & 0.21 & 0.01 & 0.01 & 0.39 \\
\hline
\end{tabular}

In applied load, stress applied was transferred through the friction (clamped load), then bearing occurred primarily in Bolt 1 but Bolt 2 (to lesser extend in Bolt 3) still able to transfer stress through friction. Then, the hole clearance was taken up at Bolt 1 until completed applied load. However, secondary bending in bottom plane gives larger bending deformation than top plane as far field stress is applied as results from edge lifting.

\section{Conclusion}

As conclusions, 3-D FEA modelling has been carried out to determine the stress distribution in multi-bolted joints to explicitly includes friction load transferred through plate thickness to provide a precise and reliable stress distribution results. Stress analysis study able to predict the failure path occurred based on its highest stress exhibited along the hole boundary. The highest tangential stress was exhibited at the outer bolts and this is consistence with experimental observations. Moreover, staggered configuration showed the larger tangential stress than non-staggered configuration and increasing number of bolts produced higher bypass stress transfer to adjacent bolts. Effects of secondary bending is more prominent in cross-ply and thinner plates due to implementation of smeared-out properties gives less good results in larger secondary bending models. However, the effects from secondary bending is not much significant compared to single-bolt joint. 


\section{Acknowledgement}

The authors would like to acknowledge Universiti Tun Hussein Onn Malaysia for providing laboratory facilities and financial assistance under project Vot No. U549.

\section{References}

[1] Tripathy DK \& Saho BP (2017), Properties and applications of polymer nanocomposites. Springer-Verlag Berlin Heidelberg 1-21.

[2] Supar K \& Ahmad H (2017), 3-D modelling of single-lap multibolted joints under quasi-static conditions. AIP Conference Proceedings, 1885 1-8.

[3] Ahmad H (2016), Stress distribution of secondary bending in single-lap bolted joints with dissimilar joining plates and plate types. Journal Teknologi 78(6), 1-7.

[4] Anders HR \& Ahmad H (2016), Notched strength of woven fabric kenaf composite plates with different stacking sequences and hole sizes. Matec Web of Conferences, EDP Sciences 10, 1-6.

[5] Cunningham D, Harries KA \& Bell AJ (2015), Open-hole tension capacity of pultruded GFRP having staggered hole arrangement. Engineering Structures 95, 8-15.

[6] McCarthy CT \& Gray PJ (2011), An analytical model for the prediction of load distribution in highly torqued multi-bolt composite joint. Composite Structures 93(2), 287-298.

[7] Zhou Y, Nezhad HY, Hou C, Wan X, McCarthy CT \& McCarthy MA (2015), A three dimensional implicit finite element damage model and its application to single-lap multi-bolt composite joints with variable clearance. Composite Structures 131, 1060-1072.

[8] DeJong T (1977), Stresses around a pin loaded hole in elastically orthotropic or isotropic plates. Journal Composite Materials 11, 313-331.

[9] Smith PA, Ashby MF \& Pascoe KJ (1987), Modelling clamp-up effects in composite bolted joints. Journal of Composite Materials $21,879-897$.

[10] Ahmad H, Crocombe AD \& Smith PA (2014), Smith, Strength prediction in CFRP woven laminate bolted double-lap joints under quasi-static loading using XFEM. Composites Part A 56, 192-202.

[11] Ahmad H, Crocombe AD \& Smith PA (2014), Strength prediction in CFRP woven laminate bolted single-lap joints under quasi-static loading using XFEM. Composites Part A: Applied Science and Manufacturing 66(7), 82-93.

[12] Feo L, Marra G \& Mosallam AS (2012), Stress analysis of multibolted joints for FRP pultruded composite structures. Composite Structures 94, 3769-3780.

[13] Yun JH, Choi JH \& Kweon JH (2014), A study on the strength improvement of the multi-bolted joint. Composite Structures 108, 409-416.

[14] Supar K \& Ahmad H (2018), Strength predictions of multi-bolted joints in woven fabric kenaf composite plates with different configurations using XFEM frameworks. Journal Trends in Textile Engineering \& Fashion Technology 2, 1-10.

[15] American Institute of Timber Construction (2005), Timber Construction Manual, Fifth edition, John Wiley \& Sons, Hoboken, New Jersey 239-269.

[16] ABAQUS®V. 6.13.1, User's Manual and Theory Manual. Dassault Systèmes Simulia Corp., Providence, RI. 